\title{
MAKING STUDENT EXPLANATIONS RELEVANT IN WHOLE CLASS DISCUSSION
}

\author{
Jenni Ingram,_Nick Andrews and Andrea Pitt \\ University of Oxford
}

\begin{abstract}
Students explaining their mathematics is vital to the teaching and learning of mathematics, yet we know little about how to enable and support students to explain in whole class discussions beyond teachers asking particular questions. In this chapter we use a conversation analytic approach to explore the interactional structures that make student explanations relevant. Through a detailed examination of interactions where a student explanation occurs, three distinct structures are identified where a student explanation is perceived to be relevant Our focus in the analysis is the social actions students themselves do in their explanations to display their interpretation of the interaction as requiring an explanation and constraining the type of explanation. However, these structures also offer ways that teachers can use the structure of interaction to encourage students to offer explanations in their responses.
\end{abstract}

\section{INTRODUCTION}

Students' explanations can be used by teachers to both monitor and respond to students' mathematical thinking and adapt their teaching in light of this (Franke, Fennema \& Carpenter, 1997). Describing, explaining and justifying can also help students develop their mathematical understanding (Rogoff, 1991; Sidney, Hattikudur \& Alibali, 2015). The act of students providing explanations for their answers has also been shown to be positively related to achievement outcomes (Webb \& Palincsar, 1996). New mathematics curricula promote increasing the lucidity of students' explanations, broadening their mathematical vocabulary, and more generally developing and communicating their mathematical understanding. However, most research into student explanations has either focused on the questions and prompts that teachers can ask so as to develop students' reasoning (e.g., Franke et al., 2009) or on the nature of the mathematical tasks that students engage with in their mathematics lessons. In these studies the teacher is explicitly inviting an explanation and the focus of the research has been specifically on the actions of the teacher. Yet student explanations are given by students, and do not always immediately follow an explicit initiation by a teacher.

In this paper we take a conversation analytic (CA) approach in order to examine the sequences of interaction during whole class discussions in which a student explanation occurs. Using the CA ideas of conditional relevance and preference we examine the structures within these interactions that mean that a student explanation is (conditionally) relevant. Other research analysing classroom interaction has focused either on categorising the types of explanations that students offer (Drageset, 2015) or on how teachers respond in the turn that follows (Franke et al., 2009; Lee, 2007). Here, we focus on the interactions that lead up to a student explanation that make a student explanation relevant during whole class interactions in mathematics lessons. This shifts the emphasis away from what teachers have done to generate student explanations. Instead the focus is on how students themselves use explanations to display their interpretation of the interaction through how they construct their 
responses. This approach emphasises the social action of justification and explanation, rather than a cognitive approach focusing on what students know or understand.

\section{THE STRUCTURE OF CLASSROOM INTERACTION}

The most common structure in pedagogic interactions is the well-known three-part IRF (InitiationResponse-Feedback) (Sinclair \& Coulthard, 1974; c.f., IRE, Mehan, 1979, and "triadic dialogue", Lemke, 1985) sequence. This structure continues to dominate many classrooms and according to Wells (1993) "if there is one finding on which students of classroom discourse agreed, it must be the ubiquity of the three-part exchange structure" (p.1). Numerous researchers (e.g., Nystrand \& Gamoran, 1991) have criticised this structure as a teacher-dominant practice and question its role in meaningful student participation. Others, however, consider how the IRF sequence can be used as a teaching tool to guide a class of students toward the common goal of learning (Mercer, 1992; Nassaji \& Wells, 2000; Lee, 2007).

IRF is not, however, the only interaction that takes place in the classroom (Cazden, 2001) and neither is it a single sequence type (Waring, 2009). The teacher "initiation" turns of IRFs (Mercer \& Littleton, 2007; Milani, 2012) and the students' response turns (Drageset 2015; Franke et al. 2009) carry out different types of actions, as do the third turns from the teacher which may launch a range of teaching activities (Lee, 2007; Nassaji \& Wells, 2000). Whereas most of these studies focus on the categorisation of each turn in isolation, a CA approach focuses on the sequence of turns and the reflexive relationship between them. In particular, how participation in the IRF structure displays students' and teacher's actions and their interpretation of the turns that have gone before and constrain those that follow. The focus here is on how the students' response turns display the ways in which they understand the interactional context and act upon the turns that came before it. Specifically, how they use explanations to display their understanding of what their response needed to include. It is not about how these turns can be characterised with reference to categorical constructs. Although the analysis is not restricted to student explanations that arise within an IRF structure, the IRF categorisation does serve to simplify the structure of the interaction. Spoken interaction, and classroom interaction specifically, is inherently messy. Responses do not always directly follow the initiation, they can take several turns to be formed, and in classrooms responses can come from multiple speakers as well as single students. CA takes into account this messiness by focusing on the multiple actions performed by each turn and the sequential context within which the turns occur. In other words, it considers what the explanation is doing by being produced in that particular turn and in that particular way, in relation to the turns that have come before and those that might follow.

Whilst the ubiquitous nature of the IRF sequence alongside other underlying interactional structures imply some stability and reliability in classroom interaction, what teachers and students do in their turn positions is not predictable because it is contingent upon the immediate sequential context in which it occurs. Whilst it might be possible to predict that a student's response to a teacher's question will be an answer, it is not possible to predict the nature or form of that answer. Any predictability comes from the sequence of turns within which the turns occur, not from their categorisation as an initiation, response, or feedback move. The sequential context encompasses all those turns that influence the design and structure of the turns being considered. 
In this chapter, we take a very broad definition of explanation as outlined below. In particular, the term 'student explanation' includes both turns that explain something and turns where there is disagreement between speakers. In ordinary conversation an explanation is given to address an assumed knowledge deficit in the other participants in the interaction (Antaki 1994) and a distinction is often made between explanations and arguments (Quasthoff et al 2017). This distinction is not necessarily easy to make in the case of the classroom. Students can offer explanations to display their own knowledge without the requirement that there is a knowledge deficit in the other participants, for example the teacher. Explanations can also be given for why the student has given a particular answer, as well as for why a particular answer is valid. Furthermore, the distinction between an explanation and an argument can often only be made as the sequence unfolds as the nature of the disagreement that is the marker of an argument is not always immediately apparent in the interaction.

\section{METHODS}

To illustrate the different sequential contexts within which student explanations are made relevant we draw upon data from a corpus of transcripts from mathematics lessons in the UK with secondary aged students (11-18 years old) which were products of several different studies. Each study involved the video recording of naturally occurring mathematics lessons but the overall aims of the studies and how the data was to be used varied between the projects. The lessons were naturally occurring in that there was no specific intervention or direction as to what should be taught or how it should be taught. In each case the teacher chose which lesson(s) with which class would be video recorded. The lessons came from teachers with a range of teaching experiences: some have taught for only 2 years whilst another has taught for over 30 years. The schools involved varied from state comprehensive schools serving areas with high levels of social deprivation, to a fee-paying selective boarding school. One aim of the current analysis was to look at commonalities in the structure of interactions around students' turns that include explanations across this diverse range of mathematics classrooms. All whole class interactions from these videos were transcribed using Jefferson (1984). In the extracts below the transcription has been simplified for ease of reading and the notation used is given at the end of this chapter.

The analysis takes advantage of conversation analytic methods to examine and specify the local contingencies that surround a student's explanation in order to identify the features of talk that make an explanation relevant. The approach is inductive with the focus of the analysis arising from 'unmotivated looking'. Initially turns where students were 'doing' explaining were identified, and these were then examined within their sequential context. A key principle of CA is that interactions cannot be adequately understood except by consideration of the sequential context in which they occur. Participants design their contributions to an interaction in light of the local context, particularly the other participants and the turns that have occurred before. These contributions then form part of the context for subsequent turns. These ideas emphasise the ethnomethodological roots of CA in that the focus is on how the participants themselves interpret the interactions, rather than the researcher. Hence, the focus of the analysis are those sequential contexts where students interpret the interaction as making an explanation relevant by offering (or attempting to offer) this explanation.

This analysis draws upon two key ideas from CA research, conditional relevance and preference. These two ideas describe the structure of the interactions rather than their usual psychological use. Within the IRF framework the response turn is conditionally relevant after the teacher has taken the 
initiation turn in that, following the initiation, a response is expected, or an account for why it cannot be given (Schegloff, 2007). Similarly, the third turn is conditionally relevant after the student has given the response turn. This is another way in which interactional structures in classrooms are different from those in ordinary conversation. Whilst a response is always conditionally relevant after an initiation, only in a teaching and learning interaction like those in classrooms is a third turn conditionally relevant following the response. So in exploring what makes a student explanation relevant we are examining the interactional structures within which the student displays this relevance in the way in which they construct their turn. In particular we are seeking whether there are features of the interactional context that students treat as making some form of explanation in their turn at talk as relevant.

Preference refers to the idea of affiliative and disaffiliative social actions, rather than the liking or disliking of the action. "There is a "bias" intrinsic to many aspects of the organisation of talk which is generally favourable to the maintenance of bonds of solidarity between actors and which promotes the avoidance of conflict' (Heritage, 1984: 265). Certain responses to a teacher's initiation are preferred over others and these responses are usually affiliative and contribute to moving forward the interaction such as along a coherent and/or logical line of reasoning consistent with content-related goals of the lesson. A preferred response in this sense is one that is 'noticeably absent' when it is not given (Bilmes, 1988), principally because without such a response there is discontinuity in the line of reasoning that is being co-constructed by the teacher and students. In this sense, a preferred response could include errors or misconceptions if the teacher treats them as such by using them to move the learning towards their goals. But in classrooms where there are strongly established norms of turn taking, a secondary meaning of preference relates to whether the positioning of a response is consistent with the normative structure of talk in that classroom. In this case, the absence of a preferred response would be notable by an extended silence or lapse (Ingram \& Elliott, 2014) or through a different student to the one the response was requested from offering a response. However, students do not always give a preferred response (or cannot) but the level of disaffiliation can be minimised if the dispreferred response includes an account or explanation. As with conditional relevance, we also examine interactional structures for features that students treat as signals that to include some form of explanation in their turn at talk is preferred, in the sense of progressing the conversation.

A defining challenge to this approach is identifying when student turns include explanations. Traditional categorisations, such as that offered by Drageset (2015), focus on the content of explanations but also fails to recognise unsuccessful attempts by students to offer an explanation, for example, when a student just says 'because...'. Explanations can also be formed over several turns and therefore categorising individual turns would also miss contexts where students perceive an explanation to be relevant. Therefore we took a broad approach to identifying sequences of turns that included student explanations. Initially we included all sequences where a student turn included a marker that might indicate an explanation, such as because, 'cause, therefore, and so (the marker hence did not occur in the data). We also included all sequences where a student turn included more than two words to ensure that we did not miss explanations that did not use the traditional markers. The sequences of turns collected could include more than one student explanation, from one student or from several students due to the broad sense of interactional context used by CA. The analysis then 
progressed to identifying the interactional structures that made that student explanation(s) relevant which occurred in the lessons of at least two different teachers.

\section{FINDINGS}

Three distinct interactional structures were identified within which a student included some form of explanation in a turn of talk. The first of these is where the student treats the teacher initiation turn as a direct signal that some form of explanation is relevant. Different forms of explanation might be offered within this structure as exemplified in due course. The second and third structures relate to where a student responds to an issue of preference by offering an explanation in their turn. In the second structure an explanation is used by the student to mitigate a dispreferred response they are giving which can arise in a range of interactional contexts, and in the third structure the explanation follows an indication that the original response given was not the preferred response. Each of these structures is discussed in turn below.

\section{Teachers explicitly requiring an explanation}

In the data the vast majority of student explanations follow a teacher's initiation that makes an explanation explicitly conditionally relevant; often one that asks a why or how question. The asking of such questions, or a prompt that explicitly asks for a reason or an explanation, makes an explanation or reason conditionally relevant in the second turn. The student is expected to include a reason or explanation in their response.

1 T: okay Gabe. could you explain to me why (.) a quarter is, finding a quarter of something is (.) exactly the same as multiplying by point two five

$2 \quad$ S: $\quad$ er cause Tom said (.) er if you times a number say twelve by one it would equal the same. if you times it by more than one it would be more than that number. and if you times it by less than one but more than zero it would be er below the number ((inaudible))

\section{Extract 1 - Teacher A}

In Extract 1 the teacher explicitly asks for an explanation as well as asking why. Grammatically this is not a question but a request and an explanation is made relevant in the turn that follows. It is perhaps unsurprising that in these contexts students interpret the situation as needing an explanation and demonstrate this by including some form of explanation in their response. There is, however, considerable variation in the nature of explanations given by students. In Extract 2 the teacher also explicitly asks for an explanation but the response gives an explanation for why the student thought the answer was negative, not for why the answer was negative. The student has given a matched response in terms of the interactional structure, but not necessarily the response the teacher was anticipating.

$$
\begin{array}{lll}
1 & \mathrm{~T} & \text { why is it minus } \\
2 & \mathrm{~S}: & \text { because he just told me }
\end{array}
$$

Extract 2 - Teacher E 
We do not consider the nature or quality of the student explanations in these scenarios here but this is considered elsewhere (Ingram, Andrews \& Pitt 2016; Drageset 2015). These contexts also give rise to failed attempts to give explanations, where the student has indicated that they see an explanation as relevant but does not actually give an explanation (e.g., 'because...'). In the first interactional structure the relevance of an explanation is explicit and the preference for some type of explanation over no explanation at all leads to a wide variety of explanations given, only some of which are mathematical in nature.

\section{Giving a dispreferred response}

Explanations or reasoning are also conditionally relevant when someone is giving a dispreferred response (Schegloff, 2007). This is particularly evident when a student is giving a response to a question that has already been responded to by another student earlier in the interaction. The current student needs to account for why their response is needed. By offering an explanation in their turn the student is showing that their response can be treated as dispreferred and are constructing their turn to mitigate this. This is the case both where the student has interepreted the context as needing to develop the previous student's responses in order to move the interaction forward, and also when they are offering a different, perhaps contradictory, response - again to contribute to the interactional trajectory of the lesson. By answering a question that has already been answered the student is treating this previous response as problematic in some way and therefore ensigns their turn to deal with the problem whilst minimising the disaffiliative nature of treating a peer's turn as problematic. The need for an explanation arises from a desire to mitigate the dispreferred nature of the response given and therefore this expectation for an account or explanation exists irrespective of whether the teacher prompts for it in a turn subsequent to the original student's response.

$\begin{array}{lll}1 & \text { T: } & \text {.. Michael do you think that's true or false } \\ 2 & \text { S1: } & \text { true } \\ 3 & \text { S2: } & \text { true 'cause there's only three outcomes to get so we-. } \\ & & ((\text { transcript omitted })) \\ 4 & \text { S2: } & \text { so it couldn't be unfair because its true its gotta be one third } \\ 5 & \text { T: } & \text { ok does everybody else agree with that? } \\ 6 & \text { S3: } & \text { no I don't. you've gotta say, imagine if it was like a good team and then a rubbish } \\ & & \text { team. So they could lose. Like Accrington and Stanley }{ }^{1} \text {. }\end{array}$

Extract 3 - Teacher E

In Extract 3 the nominated student gives the answer to the question asked by the teacher in line 2 . Another student, who was working with the first student on the task as a pair, then self-selects to repeat the answer and then add an explanation. The teacher has not explicitly asked for the explanation but the explanation adds to the answer given by the student's partner, S1. Another explanation is offered by a third student in line 6 , which contrasts with the first two answers given.

\footnotetext{
${ }^{1}$ In the UK there is a well known television advert for milk where a young boy says that Ian Rush (famous footballer) said that if he didn't drink lots of milk he would only be good enough to play for Accrington Stanley to which the response was 'who are they', ,exactly'.
} 
The teacher offers students the opportunity to offer a contrasting answer in line 5, but again does not explicitly ask for an explanation. In each case the explanation is part of a turn that dispreferred. In the first situation in line 3, the student had not been nominated to speak and had self-selected, and so is dispreferred because it is inconsistent with the normative structure of turn taking in this classroom. The explanation offers both an account for why they needed to speak in that they added to their partner's response and an explanation for why the statement is true. In the second situation the student was giving a contradictory answer to the answer offered by the two students before and is therefore not an affiliative action towards the other two students. Whilst this new answer contributes to the trajectory of the lesson, it is marks out a discontinuity in the line of reasoning and consequently requires some form of account or justification.

Often teachers generated this expectation of an account through the posing of questions or tasks where different answers are either possible, such as an open question with multiple answers, or questions where a point of contention is likely to arise. These questions or tasks then offered more of an opportunity for students to give different responses to the same initiation. However, the account for giving a dispreferred response was not always accepted. In Extract 3 the omitted transcript includes an interaction between several students which indicates that the turn is treated as dispreferred by the other students, who tell each other to 'shut up' or similar.

Another situation where an explanation is used by a student to mitigate a dispreferred response arose where the student is giving a response that might alter the trajectory of the lesson, something that is usually tightly controlled by a teacher (Zemel and Koschmann, 2011). In Extract 4 the students are identifying a missing value when given an incomplete data set and the average of that data set. The discussion so far has focused on the mean.

44 T: $\quad$ so then, we know this. you know that those four add up to two hundred and seventy one, so then I suppose what you could do is say that two hundred and seventy one plus the maths mark, well has got to equal three hundred and fifty doesn't it. does that make sense? yeah Simon.

45 Ss: yeah

46 S: it could also be seventy one just because the question doesn't specify which average

47 T: hold on. we're going back to that, we will go back to that. let's do this one. so, what is that number.

\section{Extract 4 - Teacher S}

In line 46 the student is shifting the line of reasoning to another average, the median. His turn begins with an answer to the question that has generated the preceding discussions before accounting for where his answer has come from, and why it is another acceptable answer. This is similar to the situation above where the student is offering an explanation when they are speaking despite their partner being asked to speak. In both situations the right or authority of the teacher to control classroom interactions, whether that is the turn taking or the topic, is being challenged and the explanations serve to mitigate this challenge. 


\section{Students continuing their turn}

Finally, student explanations also become relevant when the expectation of them adding to their previous response arises, without the teacher necessarily explicitly asking for the explanation. This occurs when the turn to talk is returned to the student when it would normally be expected to return to the teacher (see McHoul (1974) for a detailed description of who can take turns when in classrooms). In the extract below there are two structural mechanisms that result in the turn returning to the student and them adding to their earlier response.

$\begin{array}{lll}1 & \text { S: } & \text {..I did nought point one was how long the blink would be } \\ 2 & & (0.9) \\ 3 & \text { T: } & \text { right } \\ 4 & & (0.8) \\ 5 & \text { S: } & \text { ti:mes }(0.6) \text { a hundred }(0.8) \text { because that's how fast it was going } \\ 6 & \text { T: } & \text { so you did nought point one times a hundred } \\ 7 & & (1.8) \\ 8 & \text { S: } & \text { te:n }(0.7) \text { because I converted that into metres }\end{array}$

Extract 5 - Teacher R

Firstly, there are several pauses in the dialogue of Extract 5 where the teacher would usually take the next turn: 0.9 seconds in line 2, 0.8 seconds in line 4, 0.8 seconds in line 5, 1.8 seconds in line 7 and 0.7 seconds in line 8 . In each case, the pause indicates that the teacher is not going to take the turn as expected and therefore the turn returns to the student (see Ingram \& Elliott (2014) for a further explanation of why this occurs). This is supported further in line 3 where the teacher uses a continuation marker to indicate that he expects the student to continue. What the student does with the turn once it returns to them depends upon how they have interpreted the interaction that has led to this. The fact that the teacher has not taken the turn as expected indicates that there is some sort of trouble in the interaction and the silence is indicative of the absence of a preferred response. The student could interpret this as their answer not being acceptable in the sense of developing the line of reasoning, either because they have not included enough information, because there is an error in it, or because the teacher has not understood how they have phrased it. Most of these sources of trouble result in the student adding more clarification, such as an explanation, more information or some justification for their original response (Ingram \& Elliott, 2016). In some cases it can result in students offering a different answer to the original question asked.

\section{CONCLUSION}

In this paper we have identified three interactional structures that make student explanations conditionally relevant during whole class discussions. The first of these, where an explanation is explicitly asked for, has already been the focus of much research looking at the types of questions or prompts teachers can use that support students in giving their explanations. However, there is variation in the nature of the student explanations that follow as illustrated in Extracts 1 and 2. So whilst an explanation is conditionally relevant in the student's turn, there is not a simple 
correspondence between the type of question or prompt given by the teacher and the form of the student's explanation. An apparently straightforward 'why' question from the teacher makes logical (as in Extract 1 above), non-mathematical (as in Extract 2) and procedural explanations (what procedure was followed to get an answer) all conditionally relevant. Thus the student treats a 'why' question as a signal that some form of explanation is relevant, but only where the teacher initiation restricts these options does an explanation in the form of logical reasoning become conditionally relevant.

In the second interactional structure the student designs their turn as a dispreferred turn but mitigates the disaffiliative nature of the turn by adding an explanation. This turn could be dispreferred because the student did not have the right to speak but could also be a consequence of repeating an answer that has already been given and hence needing additional information to justify the repetition. In these cases the dispreference relates to the need to move the interaction forward in line with the goal of the lesson. The turn could also be dispreferred where it is offering a contrastive answer to another student (or the teacher). Here the dispreference relates to the affiliative action the turn is doing, and an account is needed to reduce the disaffiliative nature of the turn.

In the third structure using pauses or continuation markers to return the turn to the student results in the student needing to add to or alter their response. Here the disruption to the turn-taking structure of the IRF sequence indicates some sort of trouble with the student's response to the teacher's initiation that is preventing the final feedback turn by the teacher. The teacher is treating the student's response as dispreferred. In this case, the student treats the teacher refraining from taking the turn, as a signal to include an explanation in their next turn.

While our focus was on distinct interactional structures within which a student included some form of explanation in a turn of talk, each of these structures is manipulable by teachers within the structure of the IRF. Through the teachers' design of their initial turn, through the use of insertion IRF sequences prompting other students to build on or challenge the initial response to the initiation, or through the delaying (or omission) of the feedback turn. Future work in this project includes working with teachers in order to make use of these structures when supporting and encouraging student explanation and justification. Initial analysis of the current data indicates that there is wide variation in the nature of explanation following a teacher's explicit request for one. Explanations that occur in the other two structures are frequently about the mathematics, but include examples where the explanation is purely a description of the procedure used, and occasionally includes examples where the interaction breaks down. Further research is needed to examine how the qualities of the explanation varies within these structures, and how these qualities are a consequence of the preceding interactions.

\section{Transcription Conventions}

Taken from G. Jefferson (1984), Transcription notation, in J. Atkinson and J. Heritage (Eds.), Structures of social interaction, New York: Cambridge University Press.

\section{Convention Name \\ [ text ] Brackets \\ $=\quad$ Equal Sign}

Use

Indicates the start and end points of overlapping speech.

Indicates the break and subsequent continuation of a single utterance. 


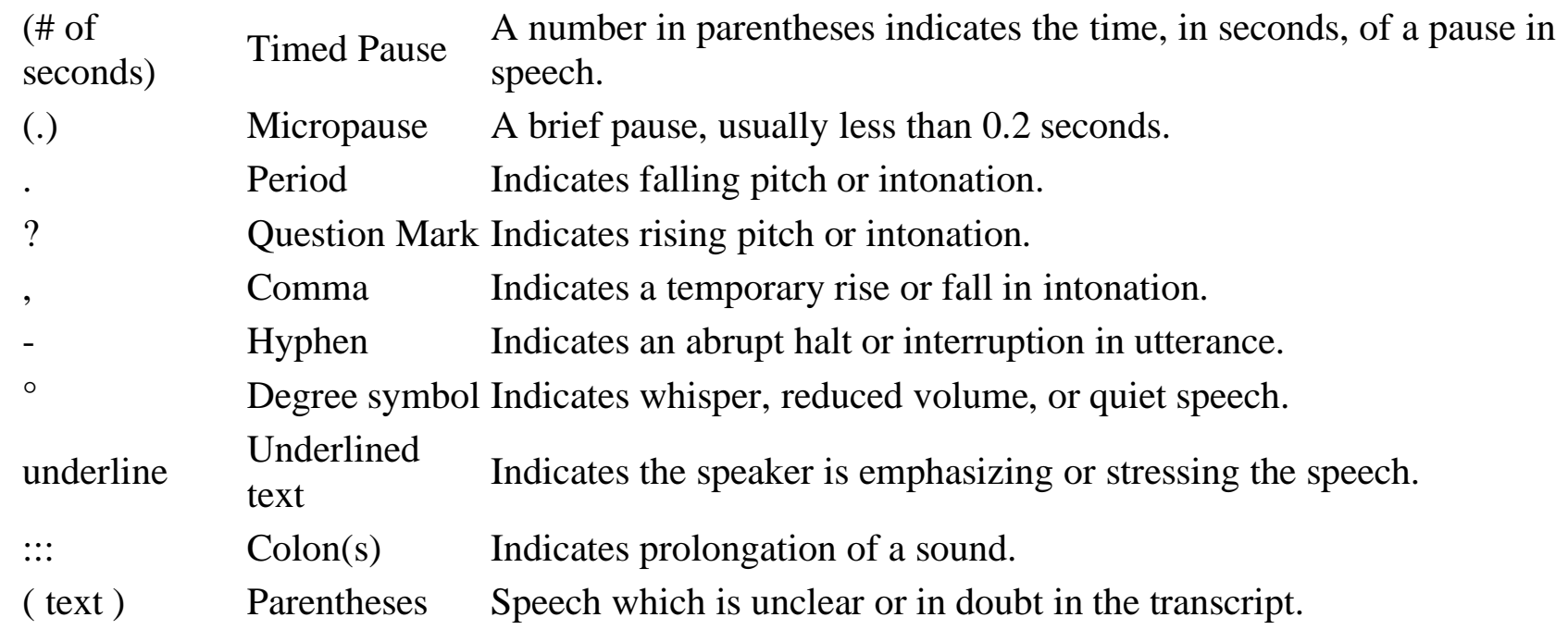

\section{References}

Antaki, C. (1994). Explaining and arguing: The social organization of accounts. London: SAGE.

Bilmes, J. (1988) The concept of preference in conversation analysis. Language in Society, 17(2), 161-181

Cazden, C. B. (2001) Classroom discourse: The language of teaching and learning. Westport: Heinemann.

Drageset, O. G. (2015). Different types of student comments in the mathematics classroom. Journal of Mathematical Behaviour, 38, 29-40.

Franke, M. L., Webb, N. M., Chan, A. G., Ing, M., Freund, D., \& Battey, D. (2009). Teacher questioning to elicit students' mathematical thinking in elementary school classrooms. Journal of Teacher Education, 60(4), 380-392.

Franke, M. L., Fennema, E. \& Carpenter, T. P. (1997). Teachers creating change: Examining evolving beliefs and classroom practice. In E. Fennema \& B. S. Nelson (Eds.), Mathematics teachers in transition (pp.255282) Mahwah, NJ: Lawrence Erlbam Associates.

Heritage, J. (1984). Garfinkel and ethnomethodology. Cambridge: Polity.

Ingram, J., Andrews, N. \& Pitt, A. (2016). Patterns of interactions that encourage student explanations in mathematics lessons. In G. Adams (Ed.) Proceedings of the British Society for Research into Learning Mathematics, 36(1), 42-47

Ingram, J. \& Elliott, V. (2014). Turn taking and 'wait time' in classroom interactions. Journal of Pragmatics $62,1-12$.

Ingram, J. \& Elliott, V. (2016). A critical analysis of the role of wait time in classroom interactions and the effects on student and teacher interaction. Cambridge Journal of Education, 46, 1-17.

Lee, Y-A. (2007). Third turn position in teacher talk: Contingence and the work of teaching. Journal of Pragmatics, 23, 55-69.

Lemke, J. L. (1985). Using language in the classroom. Geelong, Victoria, Australia: Deakin University Press.

McHoul, A. (1978) The organization of turns at formal talk in the classroom. Language in Society, 7, 183213.

Mehan, H. (1979). Learning lessons: Social organization in the classroom. Cambridge, Mass: Harvard University Press. 
Mercer, N. \& Littleton, K. (2007). Dialogue and the development of children's thinking: A sociocultural approach. London: Routledge.

Mercer, N. (1992). Talk for teaching and learning. In K. Norman (Ed.), Thinking voices: The National Oracy Project (pp. 215-223). London: Hodder \& Soughton.

Milani, R. (2012). Dialogical questioning in mathematics education. In Pre-proceedings of the 12th International Congress on Mathematical Education, Topic Study Group 28, 8th -15th July, COEX, Seoul, Korea.

Nassaji, H. \& Wells, G., (2000). What's the use of 'triadic dialogue'?: An investigation of teacher-student interaction. Applied Linguistics, 21(3), 376-406.

Nystrand, M. \& Gamoran, A. (1991). Instructional discourse, student engagement, and literature achievement. Research in the Teaching of English, 25, 261-90.

Quasthoff, U., Heller, V. \& Morek, M. (2017). On the sequential organization and genre-orientation of discourse units in interaction: An analytic framework. Discourse Studies, 19(1), 84-110.

Rogoff, B. (1991) Guidance and participation in spatial planning. In L. B.Resnick, J. M. Levine, \& S. D. Teasley (Eds.). Perspectives on socially shared cognition (pp. 349-383). Washington DC: American Psychological Association.

Schegloff, E. A. (2007). A primer for conversation analysis: Sequence organization. Cambridge, England: Cambridge University Press.

Sidney, P. G., Hattikudur, S. \& Alibali, M. W. (2015). How do contrasting cases and self-explanation promote learning? Evidence from fraction division. Learning and Instruction, 40, 29-38.

Sinclair, J. \& Coulthard, M. (1975). Towards an analysis of discourse: The English used by teachers and pupils. Oxford: Oxford University Press.

Waring, H. Z. (2009) Moving out of IRF: A single case analysis. Language Learning, 59(4), 796-825.

Webb, N. M., \& Palincsar, A. S., (1996) Group processes in the classroom. In D. Berliner \& R. Calfee (Eds.), Handbook of educational psychology (pp. 841-873). New York: Macmillan.

Wells, G. (1993). Reevaluating the IRF sequence: A proposal for the articulation of theories of activity and discourse for the analysis of teaching and learning in the classroom. Linguistics and Education, 5, 1-37.

Zemel, A. \& Koschmann, T. (2011). Pursuing a question: Reinitiating IRE sequences as a method of instruction. Journal of Pragmatics, 43, 475-488. 